\title{
Luces y sombras del arbitraje institucional en la Administración General del Estado*
}

\author{
Marta García Pérez \\ Profesora Titular de Derecho Administrativo \\ Universidad de A Coruña
}

SUMARIO: I. GUESTIONES PREVIAS. II. ¿ARBITRAJE INSTITUCIONAL? III. LA NATURALEZA JURÍDICA DE LA TÉCNICA PREVISTA EN LA DISPOSICIÓN ADICIONAL ÚNICA DE LA LEY 11/2011. IV. ÁMBITO SUBJETIVO. V. ÁMBITO OBJETIVO. VI. LA COMISIÓN DELEGADA. VII. REFLEXIÓN FINAL.

\section{RESUMEN}

El presente trabajo analiza la disposición adicional única de la Ley 11/2011, de 20 de mayo, que introduce un procedimiento de resolución de las controversias surgidas entre la Administración pública y sus entes instrumentales. La regulación adolece de vicios formales y de fondo que pueden dificultar su aplicación. Unos y otros son estudiados a la luz de la jurisprudencia y la doctrina.

Palabras clave:

Administración pública, entes instrumentales, resolución arbitral de conflictos.

\section{ABSTRACT}

This research analyzes the provision of Law 11/2011, of May 20, which introduces a procedure for resolution of disputes between public administration and its public agencies. The regulation is defective and those defects can hinder its implementation. All these questions are studied in the light of the jurisprudence and doctrine.

\footnotetext{
* Este trabajo ha sido realizado en el marco del Proyecto de Investigación fundamental no orientada "El Derecho Administrativo bajo el prisma del principio de buena Administración", financiado por el Ministerio de Ciencia e Innovación, Plan Nacional I+D+i 2008-2011 (ref.: DER2010-18993).
} 
Keywords:

Public administration, public agencies, alternative dispute resolution.

\section{CUESTIONES PREVIAS}

El Boletín Oficial del Estado de 21 de mayo de 2011 publica la Ley 11/2011, de 20 de mayo, de reforma de la Ley 60/2003, de 23 de diciembre, de Arbitraje y de regulación del arbitraje institucional en la Administración General del Estado.

Como indica el propio título de la Ley, su objeto es doble: en primer lugar, se modifica la Ley 60/2003, de 23 de diciembre, de Arbitraje; en segundo lugar, se regula un cauce procedimental para resolver los conflictos internos entre la Administración del Estado y sus entes instrumentales. Al primero se dedica el artículo único de la Ley, que se salda con diez artículos modificados y dos de nueva creación ${ }^{1}$. Al segundo objeto se dedica la disposición adicional única de la Ley, a la que nos referiremos extensamente en las páginas siguientes. Completa la reforma una disposición final que contiene, además de la referencia a los títulos competenciales al amparo de los que se ha dictado la norma y a su entrada en vigor ${ }^{2}$, la modificación de diversas leyes afectadas ${ }^{3}$.

Bajo el título "Controversias jurídicas en la Administración General del Estado y sus organismos públicos", la disposición adicional única de la Ley $11 / 2011$ establece un procedimiento específico para resolver los conflictos internos "relevantes" que se susciten entre la Administración General del Estado y sus entes instrumentales, "sin que pueda acudirse a la vía administrativa ni jurisdiccional para resolver estas controversias" (apartado 1). A tal fin se crea una "Comisión Delegada del Gobierno para la Resolución de Controversias Administrativas" (apartado 3), que dictará una resolución estableciendo de forma vinculante para las partes las medidas que cada una de ellas deberá aportar para solucionar el conflicto o controversia planteados. Dicha resolución no

\footnotetext{
${ }^{1}$ Se modifican los artículos 8, 11, 14, 15, 17, 28, 37, 39, 42 y 43 de la Ley 60/2003. Se añaden los artículos 11 bis (arbitraje estatutario) y 11 ter (anulación por laudo de los acuerdos societarios inscribibles) a la Ley 60/2003 (disposición final tercera).

${ }^{2}$ Disposición final cuarta y quinta.

${ }^{3}$ Artículo 955 de la Ley de Enjuiciamiento Civil de 1881 (disposición final primera), artículo 722 de la Ley de Enjuiciamiento Civil 1/2000 (disposición final segunda) y artículos 8.4 y 52.1 de la Ley Concursal 22/2003. (disposición final tercera).
} 
será recurrible ante los Tribunales de Justicia por las partes en conflicto (apartado 5$)^{4}$.

4 "Disposición adicional única. Controversias jurídicas en la Administración General del Estado y sus Organismos públicos.

1. Las controversias jurídicas relevantes que se susciten entre la Administración General del Estado y cualquiera de los Organismos públicos regulados en el Título III y la disposición adicional novena de la Ley 6/1997, de 14 de abril, de organización y funcionamiento de la Administración General del Estado, o las Entidades Gestoras y Servicios Comunes de la Seguridad Social u otras Entidades de Derecho público reguladas por su legislación específica que se determinen reglamentariamente, o entre dos o más de estos Entes, se resolverán por el procedimiento previsto en este precepto, sin que pueda acudirse a la vía administrativa ni jurisdiccional para resolver estas controversias.

Este procedimiento será, asimismo, aplicable a las controversias jurídicas que se susciten entre las sociedades mercantiles estatales y las fundaciones del sector público estatal con su Ministerio de tutela, la Dirección General de Patrimonio o los Organismos o entidades públicas que ostenten la totalidad del capital social o dotación de aquellas, salvo que se establezcan mecanismos internos de resolución de controversias.

2. A los efectos de esta disposición, se entenderán por controversias jurídicas relevantes aquellas que, con independencia de su cuantía generen o puedan generar un elevado número de reclamaciones, que tengan una cuantía económica de al menos 300.000 euros o que, a juicio de una de las partes, sea de esencial relevancia para el interés público.

3. Planteada una controversia, las partes enfrentadas la pondrán, de forma inmediata, en conocimiento de la Comisión Delegada del Gobierno para la Resolución de Controversias Administrativas. Dicha Comisión estará presidida por el Ministro de la Presidencia y tendrán la consideración de vocales natos el Ministro de Economía y Hacienda y el Ministro de Justicia, correspondiendo también a éste designar dentro de su ámbito al órgano que ejerza la secretaría de la Comisión. Se integrarán en la Comisión el Ministro o Ministros de los Departamentos afectados por la controversia, en los términos que se determine reglamentariamente.

4. Dicha Comisión Delegada recabará los informes técnicos y jurídicos que estime necesarios para el mejor conocimiento de la cuestión debatida. Por la secretaría de dicha Comisión se elaborarán las propuestas de decisión oportunas.

5. La Comisión Delegada del Gobierno para la Resolución de Controversias Administrativas dictará resolución estableciendo de forma vinculante para las partes las medidas que cada una de ellas deberá adoptar para solucionar el conflicto o controversia planteados. La resolución de la Comisión Delegada no será recurrible ante los Tribunales de Justicia por las partes en conflicto.

6. Este procedimiento de resolución de controversias no se aplicará:

a) A cuestiones de naturaleza penal, pero sí a las relativas al ejercicio de las acciones civiles derivadas de delitos o faltas.

b) A cuestiones de responsabilidad contable que sean competencia del Tribunal de Cuentas, sujetas a la legislación específica reguladora de éste.

c) A conflictos de atribuciones entre distintos órganos de una misma Administración pública, que se regularán por sus disposiciones específicas. 
La técnica contenida en la Ley no es improvisada. La idea de resolver extrajudicialmente los conflictos que puedan surgir entre la Administración y sus entes instrumentales había cundido ya entre un cierto sector doctrinal y, sobre todo, por razones obvias de directa implicación, en algunos estudios jurídicos promovidos desde la Abogacía del Estado. En el año 1999, en una publicación colectiva liderada por Abogados del Estado sobre La asistencia jurídica al Estado e instituciones públicas ${ }^{5}$ se trataba singularmente el arbitraje como medio de solución de controversias en las que fuese parte la Administración Pública. Particularmente, en referencia a los conflictos que opusiesen a una Administración con sus organismos públicos, o a éstos entre sí, se valoraba la posibilidad de que fuesen "resueltos en el mismo ámbito organizativo que les sirve de amparo, sin que deban llegar a formalizarse litigios ante los tribunales". Se concluía entonces que era necesario "articular un medio de solución extrajudicial de este tipo de conflictos que deben resolverse dentro de la propia organización"6. De

d) A las cuestiones derivadas de las actuaciones de control efectuadas por la Intervención General de la Administración del Estado, reguladas con carácter específico en la Ley 47/2003, de 26 de noviembre, General Presupuestaria, en la Ley 38/2003, de 17 de noviembre, General de Subvenciones, y demás normas de desarrollo de las mismas".

${ }^{5}$ Coordinada por M. PIZARRO MORENO, J.J. TORRES FERNÁNDEZ y J.I. MONEDERO MONTERO DE ESPINOSA, Ed. Aranzadi, 1999. La autoría del capítulo "El arbitraje como medio de solución de controversias cuando son parte las Administraciones Públicas, convenios de colaboración y otras fórmulas" corresponde a T. GONZÁLEZ CUETO, págs. 473 y ss.

6 T. GONZÁLEZ CUETO hace referencia en su análisis al artículo 5 de la Ley 52/1997, de 27 de noviembre, por la que se regula el régimen de la asistencia jurídica del Estado e Instituciones públicas, titulado "Contraposición de intereses", para destacar que la regulación vigente es insuficiente aun cuando apunte la posibilidad de soluciones extrajudiciales. Y añade, para terminar: "Es cierto que con arreglo a la normativa vigente resulta dificil ir más allá. Ahora bien, también es de esperar que dicho precepto pueda quedar superado próximamente". Dice el artículo 5 de la Ley 52/1997: "En los supuestos en que, ante cualesquiera órdenes jurisdiccionales, litigasen entre sí u ostentasen intereses contrapuestos las Administraciones u Organismos públicos cuya representación legal o convencional ostente el Abogado del Estado, se observarán las siguientes reglas: a) Se atenderá, en primer lugar, a lo dispuesto en la normativa especial o en las cláusulas convencionales reguladoras de la asistencia jurídica a la entidad o entidades públicas empresariales u Organismo público regulado por su normativa específica de que se trate. b) En caso de silencio de la norma o convenio, la Dirección del Servicio Jurídico del Estado, antes de evacuar el primer trámite procesal, y en atención a la naturaleza de los intereses en conflicto, expondrá a las Administraciones, entidades u Organismos litigantes su criterio tanto en cuanto a la eventual solución extrajudicial del litigio, de ser ésta posible, como, en su defecto, a la postulación que debiera asumir el Abogado del Estado, evitando en todo caso las situaciones de indefensión. Hayan o no manifestado su opinión las partes, con el informe previo de la Dirección del Servicio Jurídico del Estado, el titular del Departamento del que ésta dependa resolverá en definitiva lo procedente en cuanto a la postulación a asumir por el Abogado del Estado" (precepto desarrollado por artículo 10 del Real Decreto 997/2003, de 25 de julio). 
hecho, la Dirección general del Servicio Jurídico del Estado había llegado a elaborar un borrador de norma para dar solución a lo que se consideraba una laguna del ordenamiento jurídico, proponiendo un procedimiento que recuerda al que ahora se aprueba ${ }^{7}$.

Estas reflexiones son deudoras de una jurisprudencia que, durante la vigencia de la Ley de la Jurisdicción Contencioso-administrativa de 1956, había interpretado extensivamente la prohibición de interponer recurso contencioso-administrativo a los órganos de una entidad pública en relación con actos o disposiciones de la misma (artículo 28.4.a). El Tribunal Supremo superó las limitaciones impuestas por el tenor literal del precepto y asimiló a los órganos de la Administración aquellos entes no integrados en su estructura orgánica de cuya normativa se derivase una "relación de jerarquía o estruc-

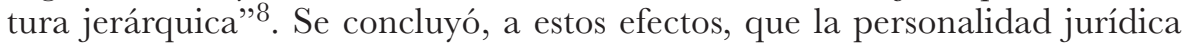
que los estatutos o normas de creación reconocían a estos entes "subordinados" operaba ad extra, pero no respecto de la organización a la que pertenecían, en cuyo caso actuaban en un plano "jerárquicamente subordinado" y frente a la cual resultaba incompatible el ejercicio de acciones contenciosas ${ }^{9}$. La invocación de la relación de jerarquía entre Administración y entes "subordinados" dejó paso a otras explicaciones más adecuadas a la autonomía y personalidad jurídica reconocida a estos entes, pero la consecuencia - prohibición de accionar- no varió un ápice. Así, el Tribunal Supremo reconoció la diferencia entre el "principio de la jerarquía en la organización administrativa" y la "tutela", que "se realiza entre entes y sujetos jurídicos diferentes, controlando por vías o mecanismos más o menos directos la actividad desplegada por el organismo sometido a tutela" ${ }^{10}$, para concluir, en de-

${ }^{7}$ En aquel borrador se proponía que si el conflicto se planteaba en el ámbito de un Departamento ministerial la competencia para resolverlo correspondía al Ministro, previa fijación de posiciones por los órganos o entidades en conflicto, debiendo informar la Abogacía del Estado ministerial o la Dirección del Servicio Jurídico del Estado. Si el conflicto excedía del ámbito de un Ministerio, se arbitraba un procedimiento en el que se daría oportunidad a los implicados de modificar su actuación y, de persistir el conflicto, previo informe de la Dirección del Servicio Jurídico del Estado y el Dictamen del Consejo de Estado, resolvía la controversia el Consejo de Ministros.

${ }^{8}$ STS de 3 de abril de 1995 (RJ 1995/2843).

${ }^{9}$ STS de 26 de julio de 1996 (RJ 1996/5720). Vid. en relación con esta sentencia el ATC 4/1998, de 12 de enero, que inadmite una demanda de amparo interpuesta contra la misma (RTC 1998/4 AUTO).

${ }^{10}$ STS de 10 de junio de 1981 (RJ 1981/2941). 
finitiva, que también en estos casos de entes tutelados debía aplicarse la regla prohibitiva de la acción del artículo 28.4.a) LJCA $^{11}$.

En todos estos casos, se imponía buscar acomodo jurídico a una realidad palmaria: junto a la Administración, otros entes de forma variada y naturaleza jurídica diversa tenían a su cargo "la prestación de determinados servicios públicos estatales o el ejercicio de actividades de cualquier clase que coadyuven a su realización" (artículo 1 de la Ley de 26 de diciembre de 1958, de Entidades Estatales Autónomas), a los que se sumaban las corporaciones de Derecho público constituidas para defender primordialmente los intereses privados de sus miembros pero que también atendían a finalidades de interés público ${ }^{12}$. En clave procesal, la amalgama de entes "descentralizados" se toparon en el contencioso con la regla prohibitiva del artículo 28.4.a) LJCA, que se utilizó en el caso de los colegios profesionales frente a actos de su Consejo General ${ }^{13}$, las Juntas de Jueces respecto a las decisiones del Consejo General del Poder Judicial ${ }^{14}$

${ }^{11}$ Con algunas matizaciones significativas. Por ejemplo, la STS de 17 de abril de 1996 (RJ 1996/3564), en la que se revoca una sentencia de la Audiencia Nacional que había declarado inadmisible el recurso planteado por una federación territorial de fútbol contra el Comité Español de Disciplina Deportiva: "La sentencia debe ser revocada, pues la referida causa de inadmisibilidad no se produce, habida cuenta de que, como señala la Sentencia del Tribunal Constitucional de 24 mayo 1985 (RTC 1985/67), "las Federaciones se configuran como instituciones privadas, que reúnen a deportistas y asociaciones dedicadas a la práctica de una misma modalidad deportiva". Tal naturaleza impide atribuirles la configuración de órganos de la Administración, pese a que, en cierta medida, desarrollen funciones públicas de carácter administrativo como es el caso de servir de vía para canalizar la asignación de subvenciones, fuera de cuyos campos actúan con plena autonomía; pudiendo recurrir las decisiones de la Administración si son contrarias a sus intereses deportivos al darse el presupuesto legitimador del artículo 28.1, a) de la indicada Ley".

${ }^{12}$ STC 76/1983, de 5 de agosto.

${ }^{13}$ Es el caso, por ejemplo, de la sentencia de 3 de abril de 1995(RJ 1995/2843), relativa a la impugnación de un Colegio de Abogados de un acto del Consejo General de la Abogacía Española: "El artículo 28.4.a) de la Ley de la Jurisdicción prohíbe interponer recurso contencioso-administrativo en relación con los actos y disposiciones de una Entidad pública a "los órganos de la misma...". (...) En este sentido es cierto que los Colegios de Abogados tienen propia personalidad jurídica, independiente de la del Consejo General ... no puede por menos de reconocerse que entre el Consejo General de la Abogacía Española y los Colegios de Abogados de ámbito provincial existe una relación o estructura jerárquica ... los Colegios de Abogados de ámbito provincial no pueden recurrir en vía contencioso-administrativa los actos del Consejo General de la Abogacía Española, en virtud de la prohibición de accionar que a los órganos de un Ente público impone el artículo 28.4.a) de la Ley de la Jurisdicción, por constituir órganos inferiores al repetido Consejo General, carentes a estos efectos de personalidad, pues ésta opera "ad extra", pero no en el interior de la Organización colegial, a cuya voluntad única es imputable su actuación en el caso concreto que enjuiciamos". 
o los organismos autónomos respecto a la Administración de la que dependí$\mathrm{an}^{15}$. En algunas ocasiones, los fallos contradictorios ponían de manifiesto la artificiosidad de las tesis jurisprudenciales o las dificultades que suponía generalizar la regla del artículo 28.4.a) a entes tan diversos. Así, por ejemplo, el propio Tribunal Supremo dictó sentencias contrarias pero muy próximas en el tiempo respecto a las Universidades cuando pretendían reaccionar contra actos o disposiciones del Ministerio de Educación y Ciencia, aplicando unas veces la regla prohibitiva del artículo 28.4.a) LJCA $^{16}$ y eludiendo otras veces su aplicación ${ }^{17}$.

14 STS de 12 de marzo de 1997 (RJ 1997/9648).

${ }^{15}$ La STS de 30 de octubre de 1982 (RJ 1982/5825) resume la tesis jurisprudencial mayoritaria sostenida respecto a la prohibición dirigida a los organismos autónomos de impugnar actos y disposiciones de la Administración de la que dependen: "si bien las normas reguladoras del referido Organismo Autónomo le reconocen personalidad jurídica distinta de la del Estado, ese reconocimiento está hecho a efectos de sus relaciones externas pero, como dice la Exposición de Motivos de la Ley de 26 diciembre 1958 citada, en su párrafo $2^{\circ}$, el reconocimiento de una personalidad jurídica distinta no supone que se trate de persona jurídica independiente del Estado; lo que coordinado con las demás normas concordantes, lleva a estimar que este Organismo integra con los demás órganos administrativos y concretamente con el Ministerio de Defensa, al que está adscrito o vinculado expresamente, la personalidad jurídica única de la Administración del Estado y no puede plantear acciones jurisdiccionales contra tal Administración del Estado, pues ello entraña que ésta se demanda a sí misma, contra lo que el citado art. 28.4.a) de la Ley Reguladora de esta Jurisdicción dispone".

${ }^{16}$ Es representativa de esta jurisprudencia la STS de 20 de enero de 1984 (RJ 1984/185), en la que se resume la doctrina aplicable: "la serena ponderación de cuanto se deja sentado y su valoración racional, conduce necesariamente a estimar que dado el régimen jurídico, organizativo y financiero de la entidad demandante que resulta de todo lo expuesto, se le ha de calificar a los efectos de que se trata de órgano de la Administración del Estado y para lo que no es óbice el hecho de la reconocida personalidad jurídica de que disfruta, ya que, de una parte, esa condición juega con plenitud de efectos sólo en sus relaciones externas o con terceros y limitadamente en cambio frente a la Administración estatal a la que está adscrito y de otra, ello no implica desvinculación e independencia absoluta del Estado, sino que por el contrario de las normas legales examinadas resulta patente una vinculación y una dependencia de la Administración General, a la que aparece sometida a través del mecanismo jurídico de la tutela; por otra parte, refuerza la tesis unitaria sustentada como fruto de los argumentos aducidos, la consideración de que la inteligencia lógica jurídica del art. 28 de que se trata, fuerza a concluir con el juicio valorativo de que "los órganos de la entidad publica" mencionados en la regla del apartado a) del párr. 4 de aquél, necesariamente habrán de ser los que por tener personalidad jurídica propia podrían estar legitimados para demandar, de no existir esta norma prohibitiva y nunca cabrá pensar que se dictó para los organismos integrados en la organización jerárquica de la Administración, puesto que su carencia de personalidad propia individualizada les priva de toda capacidad procesal y su vano intento encontraría siempre cerrado el paso por la regla del art. 27 de la Ley reguladora de la jurisdicción".

${ }^{17}$ En contraste con la tesis sostenida en la sentencia citada en la nota anterior, la STS de 10 de febrero de 1983 (RJ 1983/6022) llega a la conclusión contraria a partir de la fórmula de la 
La aprobación de la Constitución de 1978 dio un nuevo impulso a la administración instrumental y reforzó las tesis que reunían a todos sus entes bajo el paraguas de los intereses generales. En efecto, los intereses generales permitieron unificar los diferentes entes que los sirven y en cuyo servicio encuentran su justificación, cualquiera que sea la forma jurídica que adopten y el régimen jurídico a que se sometan. Al fin y al cabo, el artículo 103.1 de la Constitución dispone el sometimiento pleno a la Ley y al Derecho, pero no necesariamente al Derecho público. La forma jurídica pierde, pues, relevancia; que se adopte una $\mathrm{u}$ otra forma jurídica, o uno u otro régimen jurídico se justifica en virtud del principio de eficacia y corresponderá a los tribunales "levantar el velo" para determinar el tipo de relación existente en cada caso concreto entre los protagonistas de la controversia ${ }^{18}$.

De modo explícito, la vigente Ley de la Jurisdicción contencioso-administrativa de 1998 recoge por fin que "no pueden interponer recurso contenciosoadministrativo contra la actividad de una Administración pública", además de los órganos de la misma (apartado a del artículo 20), "las Entidades de Derecho público que sean dependientes o estén vinculadas al Estado, las Comunidades Autónomas o las Entidades locales, respecto de la actividad de la Administración de la que dependan", exceptuándose aquellos casos en que "por Ley se haya dotado de un estatuto específico de autonomía respecto de dicha Administración" (apartado c).

Esta regulación superaba, por fin, la artificiosidad de las teorías jurisprudenciales que habían tratado de encajar a la Administración instrumental en el concepto de "órganos" del predecesor artículo 28.4.a) LJCA de 1956". Pe-

personalidad jurídica: "Que antes de entrar en dicho análisis ha de efectuarse el de la inadmisibilidad opuesta al amparo del art. 28 de la Ley Jurisdiccional, por entenderse que la entidad recurrente es un órgano del Ministerio de Educación y Ciencia y por ello le está vedado la interposición de recurso contencioso-administrativo, porque es incierto ya que no es órgano del Ministerio sino Entidad Estatal Autónoma que se beneficia del régimen para las mismas establecido en la Ley de 26 diciembre y por consiguiente goza de personalidad propia incluso frente al Estado y está legitimada para la interposición del recurso conforme al art. 28.1 b) con su propia representación cual dispone el art. 35.1 por todo lo que decae la inadmisibilidad postulada del art. 82. b), no siendo relevantes, todos y cada uno de los supuestos defectos de los órganos de la Universidad en relación con su propio Estatuto y en este orden de la falta de personalidad para recurrir" (Fundamento Jurídico $2^{\circ}$ de la sentencia apelada, confirmado por el TS).

${ }^{18}$ Vid. un desarrollo de esta tesis en el trabajo de J. L. MEILÁN GIL, "La funcionalidad de los entes instrumentales como categoría jurídica", en la obra colectiva Administración instrumental. Libro Homenaje a Manual Francisco Clavero Arévalo, Cívitas, Madrid, 1994, págs.971 y ss.

19 Todavía quedan resquicios de aquella jurisprudencia. Es el caso del uso frecuente de la prohibición de impugnación de actos propios para fundamentar el artículo 20 c) LJCA Vid. S. GONZÁ- 
ro no evitó que se planteasen algunas consideraciones relevantes, en buena medida todavía abiertas, que deberán ser tenidas en cuenta para valorar adecuadamente el alcance y el acierto de la regulación del "arbitraje institucional" contenido en la Ley 11/2011.

En primer lugar, no ha existido una opinión común respecto a la naturaleza jurídica de las reglas contenidas en el artículo 20 LJCA. En los extremos de la dialéctica se posicionan quienes consideran que este artículo contiene un supuesto de falta de legitimación ${ }^{20}$ y los que reconocen que se trata simplemente de una prohibición legal de accionar ${ }^{21}$; la tesis más pragmática sostiene que la disquisición es en la práctica irrelevante ${ }^{22}$.

LEZ-VARAS IBÁÑEZ, Comentarios a la Ley de la furisdicción contencioso-administrativa (Ley 29/1998, de 13 de julio), Tecnos, 1999, pág. 212 y ss. La explicación se entiende perfectamente en el contexto de la LJCA de 1956 porque, como se expuso, permitía extender la prohibición de accionar dirigida a los órganos de la Administración hacia otras entidades que no se integraban en el complejo orgánico de la misma. En el panorama postconstitucional, la prohibición debe encontrar su justificación en la unidad de fines y en la común tarea de consecución del interés general a la que sirven todos los entes, Administraciones públicas y personas jurídicas creadas instrumentalmente para ello.

${ }^{20}$ Vid. la posición mantenida por J. GARBERÍ LLOBREGAT en la obra colectiva Comentarios a la nueva Ley reguladora de la furisdicción contencioso-administrativa, Ed. Centro de Estudios Ramón Areces, 1999, pág. 233, para quien "el ubicar sistemáticamente los supuestos del artículo 20 LJCA en el Capítulo dedicado a la legitimación -tal y como también acontecía en la LJCA de 1956-, resulta ser un verdadero acierto del legislador, pese a que lamentablemente no lo sea su concreta redacción, en el cual, en lugar de afirmarse que dichas personas y órganos no estarán legitimados activamente para promover el proceso administrativo cuando concurran las condiciones que el precepto reseña, se establece, por el contrario y muy defectuosamente, que los mismos no podrán interponer recurso contencioso-administrativo contra la actividad de una Administración Pública".

${ }^{21}$ Vid. la exposición de J. GONZÁLEZ PÉREZ en sus Comentarios a la Ley 29/1998, de 13 de julio, reguladora de la furisdicción contencioso-administrativa, Ed. Thomson-Cívitas, 6 a edición, 2011, pág. 314, en la que el autor cita a DE CASTRO para recordar que una prohibición consiste en la "inhabilitación para realizar ciertos actos en general o respecto de ciertas personas, impuestas por un veto legal". En el mismo sentido se pronuncia E. PUJALTE CLARIANA en la obra colectiva La Ley reguladora de la furisdicción contencioso-administrativa, dirigida por M. BAENA DEL ALCÁZAR, Ed. Trivium, 1ª ed., 1999, pág. 187.

22 Vid. el razonamiento de J.A. SANTAMARÍA PASTOR, en su obra La Ley reguladora de la Furisdicción contencioso-administrativa. Comentario, Ed. Iustel, 2010, pág. 253: "La finalidad de la norma es evidente: los procesos incoados por las personas y entidades mencionados en este artículo deben reputarse inadmisibles; que el fundamento de su inadmisibilidad radique en la falta de capacidad procesal, en la de legitimación o en una simple prohibición legal es, en la práctica, irrelevante; lo que interesa es examinar el contenido de estos supuestos de exclusión del recurso". 
La jurisprudencia también se ha mostrado titubeante, aunque ha declarado de modo general el carácter prohibitivo del precepto, por encima de consideraciones relativas a la falta de legitimación que podrían resultar contrarias al artículo 24.1 de la Constitución española ${ }^{23}$.

En segundo lugar, resulta esencial examinar el alcance y la extensión de tal prohibición. El enunciado básico en este punto es el siguiente: la prohibición estudiada debe limitarse a los actos dictados por la Administración matriz en el ejercicio de las funciones de tutela, control y dirección del organismo dependiente o vinculado ${ }^{24}$. Es decir, el umbral de aplicación del artículo 20.c) es estrictamente el de la llamada relación de instrumentalidad.

En palabras de MUÑOZ MACHADO ${ }^{25}$, es éste un concepto de raíz doctrinal, y asumido muy fuertemente por la jurisprudencia, que no siempre tiene

${ }^{23}$ Vid. por todas la STS de 12 de marzo de 1997, referida al derogado artículo 28.4.a) de la LJCA de 1956 pero ilustrativa de la doctrina general que ha llegado a nuestros días: “ ... este Tribunal Supremo, en su Sentencia de 11 marzo 1988 (RJ 1988/1997), estableció que el apartado a) del artículo 28.4 de la Ley de esta Jurisdicción, "no priva de legitimación a ningún órgano de carácter público, sino que, dándola por existente, les prohíbe que la ejerciten para impugnar actos o disposiciones administrativas incardinadas en la misma materia o tema de común, aunque diferenciada, competencia jerárquica". Siguiendo la doctrina de la indicada Sentencia, esta misma Sala y Sección en la de 14 mayo 1994 (RJ 1993/3946) ha declarado "que el artículo 28.4, en sus dos apartados, más que negar propiamente legitimación activa a los órganos de un Ente público o a los particulares que actúan a título de agentes o mandatarios del mismo, negativa que hoy, tras la ampliación del ámbito de la legitimación operada por el artículo 24 de la Constitución, no se acomodaría a ésta ni al derecho de "todas las personas", incluidas las jurídico-públicas, a una efectiva tutela jurisdiccional que dicha norma garantiza, dicho precepto, decimos, lo que en rigor establece, siguiendo el viejo precedente del artículo $7 .^{\circ}$ del Reglamento para la ejecución de la Ley 22 junio 1894 (que con ligeros retoques de redacción ha llegado hasta nuestros días), es el principio que prohíbe accionar frente a actos propios, partiendo de que en el supuesto de Administraciones o Entes Públicos la voluntad y la decisión administrativa es imputable al Ente como tal, no a sus órganos, y que manifestada aquélla a través del acto que agota la vía administrativa, los órganos inferiores, aunque discrepen del parecer de quien emitió el acto que puso fin a dicha vía, no pueden residenciar tal discrepancia en sede contenciosa, al integrar también la misma persona o Ente público".

${ }^{24}$ Vid. RIVERO GONZÁLEZ, M. (Coord.), Comentarios a la Ley de la Jurisdicción contencioso-administrativa, Aranzadi, Pamplona, 2002, pág. 295; ROCA ROCA, E. (Dir.), Ley 29/1998, de 13 de julio, reguladora de la Jurisdicción contencioso-administrativa, Tecnos, 2005, pág. 128; y GONZÁLEZ RIVAS, J.J. y ARANGUREN PÉREZ, I., Comentarios a la Ley reguladora de la furisdicción contencioso-administrativa, Thomson-Cívitas, $1^{\text {a }}$ ed., 2006, pág. 262 y ss.

${ }^{25}$ Vid. de este autor su Tratado de Derecho Administrativo y Derecho Público General, Tomo III, Iustel, $1^{\text {a }}$ ed., 2009, pág. 765 y ss. 
una significación igual, sino variable según el organismo o entidad al que se aplique, pero que siempre moviliza o supone la utilización de diversas técnicas. En primer lugar, los entes y organismos públicos instrumentales se crean para gestionar servicios o responsabilidades que tienen asignados las Administraciones públicas. Se rigen, en consecuencia, por el criterio de la especialidad; no tienen competencias generales sino las que le son asignadas para atender las tareas concretas que se les encomiendan. En segundo lugar, además de los condicionamientos y límites a su actividad que fijan las normas que los crean, atribuyen éstas a la Administración matriz competencias para la designación y control de sus órganos de gobierno, así como la facultad de supervisar su actividad, sometiendo a su aprobación sus planes y programas de actuación, o habilitando la posibilidad de formular directrices o instrucciones. En tercer lugar, existe asimismo una completa comunicación patrimonial y financiera entre la entidad matriz y la instrumental, de modo que aquélla provee a ésta de los recursos y medios económicos que precise para el desarrollo de sus responsabilidades $^{26}$.

Pues bien, las desavenencias derivadas de la relación de instrumentalidad no deben ventilarse por parte de la Administración matriz y los entes instrumentales en el contencioso. Prevalece en estos casos el poder de dirección que se reconoce a la Administración sobre sus entes instrumentales ${ }^{27}$ y se le reco-

${ }^{26}$ Cfr. op. cit., pág. 772. Señala el autor que este esquema general se matiza dependiendo del tipo de organismo de que se trate, por lo que debe analizarse cada caso concreto: "Existen algunas entidades públicas en las que el grado de autonomía e independencia respecto de la Administración general es tan señalado que se dota a los titulares de los órganos de gobierno de un estatuto de estabilidad, de modo que no dependa su mantenimiento de las decisiones políticas del Gobierno. Otras veces esa misma autonomía o independencia explica que la actividad de las entidades no pueda ser instruida o mediatizada mediante directrices de la Administración general. Y, en fin, también la revisión de los actos y decisiones de algunos establecimientos, o su régimen presupuestario y financiero, tienen una menor dependencia de decisiones finales de la Administración en cuyo ámbito organizativo o funcional se integran. Las aportaciones de recursos económicos también están condicionadas por las exigencias de la libre competencia en el mercado, si se trata de entidades que desarrollan actividades mercantiles".

27 Vid. extensamente un análisis de la relación entre la Administración gubernativa y la instrumental en la obra de M. MAGIDE HERRERO, Limites constitucionales de las Administraciones independientes, INAP, 2000, pág. 65 y ss. Vid. la Sentencia de 7 de febrero de 1994 (RJ 1994/1008) respecto a la relación entre un Ayuntamiento y una Gerencia de Urbanismo: "1. El fin o servicio en función del cual y para cuya gestión la Gerencia Municipal de Urbanismo fue creada es un afin o servicio propio del Ayuntamiento; en este sentido, la Gerencia en cuanto entre institucional no tiene fines propios, sino que actúa directamente los fines de sus fundadores, el Ayuntamiento. 2. Entre los dos, ente instrumental y fundador, Gerencia y Ayuntamiento, forman un 
nocerá, consecuentemente, a aquélla la capacidad para resolver las controversias unilateralmente y sin ulterior recurso; pesa sobre los entes instrumentales, correlativamente, la prohibición de accionar a la que nos estamos refiriendo en estas páginas.

Es obvio que puede hacerse una afirmación de signo contrario a la expuesta: no existirá la aludida prohibición de accionar cuando las controversias surgidas entre la Administración pública y sus entes instrumentales no se enmarquen en la relación de instrumentalidad. Esta situación es reconocida mayoritariamente por la doctrina en dos supuestos: a) cuando las entidades instrumentales actúan como sujetos de Derecho con personalidad jurídica propia, realizando fines ajenos a los de interés general que se le han encomendado; y b) cuando la Administración pública actúa en ejercicio de potestades generales que le atribuye el ordenamiento jurídico, en el ejercicio de relaciones de supremacía general. Cuestión distinta será si el proceso judicial es la vía más coherente para resolver este tipo de contiendas, pero el proceso no está en estos casos vetado a las partes contendientes.

En tercer lugar, la referencia contenida en el artículo 20.c) LJCA a las "entidades de Derecho público" que sean dependientes o estén vinculadas al Estado, las Comunidades Autónomas o las Entidades locales es, desde luego, muy limitada si la pretensión es, de modo abstracto, evitar la judicialización de los conflictos que surjan entre las Administraciones públicas y sus entes instrumentales a propósito de la relación de instrumentalidad. De ahí que se haya propuesto o reclamado la ampliación de la prohibición a los entes instrumentales, en general, superando la limitación que hoy en día existe a las entidades constituidas bajo forma jurídico-pública, salvando exclusivamente de la prohibición - como ya se hace en la redacción vigente- a los entes "a los que por Ley se haya dotado de un estatuto específico de autonomía" respecto de la Administración ${ }^{28}$.

La relación entre la entidad matriz y la instrumental es pues, clave para analizar el verdadero alcance la técnica legal contenida en la Ley 11/2011, de 20 de

\footnotetext{
"complejo organizativo unitario", lo que quiere decir que aquélla se encuentra encuadrada en la organización de ésta. 3. El ente instrumental, la Gerencia, carece de legitimación para impugnar judicialmente los actos dictados por su ente matriz y para sostener impugnaciones de la misma naturaleza en contra de los intereses de éste, pues los intereses de uno y otro o, lo que es igual, los intereses propios del ente institucional pertenecen al ente matriz que lo ha creado, que lo domina y que lo utili$z a "$.
}

${ }^{28}$ Vid. J.A. SANTAMARÍA PASTOR, op. cit., pág. 259. 
mayo que, recordemos, crea un procedimiento "arbitral" para resolver las controversias jurídicas que surjan entre la Administración General del Estado y sus entes instrumentales o entre éstos últimos. Como trataré de justificar, la regulación contenida en la disposición adicional única plantea dos graves inconvenientes:

- en primer lugar, uno de carácter cuasi-formal y, por tanto, superable: la Ley denomina "arbitraje institucional" a una técnica que no tiene nada ni de lo uno ni de lo otro;

- en segundo lugar, un obstáculo que afecta a la naturaleza misma de la técnica y que será de más difícil superación: el procedimiento regulado impide acceder a los tribunales de justicia a controversias que quedan al margen de la relación de instrumentalidad.

Estas consideraciones permitirán valorar las luces y las sombras de la técnica recogida en la disposición adicional única de la Ley 11/2011, que el propio legislador justifica en la Exposición de Motivos con las siguientes palabras:

"Es de reseñar la importancia de la disposición adicional única de esta Ley, en la que se regula un cauce procedimental de carácter ordinario e institucional para resolver los conflictos internos entre la Administración General del Estado y sus Entes instrumentales, superando los actuales mecanismos de facto, ajenos al rigor jurídico y a la objetividad que son imprescindibles en una organización que, por imperativo constitucional, ha de estar regida por el Derecho y actuar al servicio de los intereses generales bajo la dirección del Gobierno. La indudable naturaleza jurídico-pública de las relaciones de organización en el seno de la Administración hacen imprescindible un procedimiento ordinario de resolución de conflictos como el que ahora se configura, más allá de soluciones meramente parciales como pueden ser las ofrecidas por una determinada línea jurisprudencial que ha venido negando a los organismos autónomos legitimación para impugnar los actos de la Administración matriz; línea que hoy encuentra una confirmación legal en el artículo 20.c) de la Ley 29/1998, de 13 de julio, Reguladora de la Jurisdicción Contencioso-Administrativa.

Se entiende que esos conflictos deben ser resueltos por el Gobierno por lo que al efecto se crea una Comisión Delegada cuya presidencia se otorga al Ministro de la Presidencia, en su función coordinadora de la Administración General del Estado, siendo miembros natos el Ministro de Economía y Hacienda y el Ministro de Justicia. Asimismo, la secretaría se encarga al Ministerio de Justicia en atención a sus funciones y a la adscripción de los Servicios Jurídicos del Estado". 


\section{II. ¿ARBITRAJE INSTITUCIONAL?}

La expresión "arbitraje" tiene mala sombra. Me permito utilizar el calificativo para poner de manifiesto que los esfuerzos recurrentes de la doctrina y la jurisprudencia por clarificar el alcance y contenido de la técnica arbitral y permitir su normal desarrollo han venido acompasados por normas jurídicas poco clarificadoras, cuando no causantes de la confusión misma ${ }^{29}$. Su formulación como método heterocompositivo de resolución de conflictos ${ }^{30}$, en la que un tercero pretendidamente imparcial y ajeno a la controversia ofrece la solución que debe ser aceptada por los litigantes, y, sobre todo, su efecto de renuncia al planteamiento jurisdiccional de la cuestión por parte de ambos contendientes $^{31}$ no han sido atendidos por nuestros legisladores, empeñados en utilizar la expresión "arbitraje" para aludir a técnicas muy diferentes, con la consiguiente confusión.

${ }^{29}$ R. COLINA GAREA alude a esta idea de forma muy expresiva en su obra El arbitraje en España. Ventajas y desventajas, Ed. Grupo Difusión, Madrid, 2009: "se diría que el denominado sistema arbitral interno o doméstico debe sufrir algún tipo de enfermedad que le impide desarrollarse y crecer con toda normalidad, al mismo ritmo que lo hace en otros países de nuestro entorno, no necesariamente pertenecientes al commom law". Cfr. op. cit., pág. 24.

${ }^{30}$ La definición legal de arbitraje se recoge en la ya derogada Ley 36/1988, de 5 de diciembre, de Arbitraje, que no se conserva en la Ley vigente, 60/2003, de 23 de diciembre: "Mediante arbitraje, las personas naturales o jurídicas pueden someter, previo convenio, a la decisión de uno o varios árbitros las cuestiones litigiosas, surgidas o que puedan surgir, en materias de su libre disposición conforme a Derecho" (artículo 1). La Ley Modelo elaborada por la Comisión de las Naciones Unidas para el Derecho Mercantil Internacional, de 21 de junio de 1985, seguida por el legislador español de 2003, recoge una definición de "acuerdo de arbitraje" como aquel "por el que las partes deciden someter a arbitraje todas las controversias o ciertas controversias que hayan surgido o puedan surgir entre ellas respecto de una determinada relación jurídica, contractual o no contractual" (artículo 7).

${ }^{31}$ Nota que no contraviene el derecho a la tutela judicial efectiva contenida en el artículo 24.1 $\mathrm{CE}$, como ha tenido ocasión de expresar el TC en referencia al arbitraje inter privatos. En su argumentación, el TC ha considerado el carácter prestacional del derecho a la tutela judicial efectiva, el derecho a promover la actividad jurisdiccional y a renunciar a ella por los cauces que el legislador establezca. Desde esta perspectiva, el TG justifica que los titulares del derecho a la tutela judicial efectiva opten libremente por no ejercerla porque esta posibilidad está prevista en las leyes. Vid. por todas la STC 176/1996, de 11 de noviembre (F.J. 4). En ni monografia Arbitraje y Derecho administrativo, Thomson-Cívitas, 2011, analizo esta jurisprudencia constitucional y, en general, las claves constitucionales del arbitraje. 
El mejor ejemplo es el artículo 107.2 de la Ley 30/1992, tan aplaudido ${ }^{32}$ como mal entendido ${ }^{33}$, porque supuso un tratamiento a veces equivocado de la técnica creada, confundida con un arbitraje en sentido estricto a pesar de las grandes distancias que existen entre el régimen jurídico de aquel mecanismo sustitutivo de los recursos administrativos y el arbitraje cuasi-jurisdiccional ${ }^{34}$.

Con esa misma perspectiva, creo que la Ley 11/2011 contribuirá a mantener la confusión generada en torno a esta técnica, por varias razones.

32 Vid. una de las primeras reacciones en este sentido en el trabajo de M. SÁNCHEZ MORÓN, "Recursos administrativos", en la obra colectiva La nueva Ley de Régimen Furídico de las Administraciones Públicas y del Procedimiento Administrativo Común, (Dirs. LEGUINA VILLA y SÁNCHEZ MORÓN), Madrid, Tecnos, 1993, pág. 326 y ss.: “ . .. la previsión misma del artículo 107.2 constituye, sin lugar a dudas, una de las novedades y uno de los aciertos más importantes de la Ley 30/1992 en lo que se refiere al régimen de revisión de los actos en la vía administrativa, e inclusive en el conjunto de la Ley". Cfr. pág. 327.

33 Vid. extensamente GARCÍA PÉREZ, M., Arbitraje y Derecho Administrativo, Thomson-Cívitas, 2011.

${ }^{34} \mathrm{El}$ supuesto de hecho que contempla el precepto transcrito no reconoce un arbitraje, al menos en sentido estricto. A simple vista, si pretendiese regular el arbitraje estarían en entredicho algunas de las notas características de la técnica. Entre ellas, la exclusión del control judicial de la resolución arbitral y, en algunos casos, su sumisión voluntaria. Se trata, en efecto, de un específico procedimiento de impugnación en vía administrativa sustitutivo del recurso administrativo, que no puede considerarse alternativo a ni excluyente del control judicial ordinario (en este sentido, PAREJO ALFONSO, L., "Algunas reflexiones sobre el "arbitraje administrativo" a propósito de la adecuación al nuevo procedimiento administrativo común del ordenamiento de la Comunidad Autónoma de Madrid", Asamblea. Revista parlamentaria de la Asamblea de Madrid, número 1, 1999, pág. 24). Además, cuando el arbitraje se articula como cauce sustitutivo del recurso de alzada, se quiebra otra de las notas características del arbitraje -voluntariedad de sometimiento- por cuanto su ausencia determinará la inadmisión del proceso contencioso-administrativo (esta consideración es discutida por quienes consideran que necesariamente debe darse al ciudadano la posibilidad de optar por el sistema alternativo o por el recurso administrativo. Vid. por todos TRAYTER JIMÉNEZ, J.M., "El arbitraje de Derecho administrativo", Revista de Administración Pública, no 143, 1997, pág. 93: “... entendemos que el arbitraje ha de tener necesariamente carácter alternativo u optativo y, consiguientemente, no debe suponer la exclusión del recurso administrativo ordinario. Por tanto, se debe ofrecer al ciudadano la posibilidad bien de optar por el arbitraje de Derecho administrativo, bien por la vía de interponer recurso ordinario y el posterior recurso contencioso-administrativo"). De ahí que deba hablarse a lo sumo de un arbitraje impropio o atípico y de que se postule por la doctrina la utilización de una terminología diferente de lege ferenda. Coincido plenamente con BUSTILLO BOLADO, R., en el incorrecto uso legislativo del término "arbitraje" en la Ley 30/1992 y en la propuesta del autor de que de lege ferenda se sustituya por otro más adecuado, en aras de la claridad y buena técnica legislativa en el uso del lenguaje jurídico. Cfr. Convenios y contratos administrativos: transacción, arbitraje y terminación convencional del procedimiento, Ed. Aranzadi, $1^{\mathrm{a}}$ ed., 2001, pág. 296. En su $3^{a}$ edición revisada confirma la propuesta. 
En primer lugar, la regulación de la resolución de las controversias internas entre la Administración del Estado y sus entes instrumentales -o de estos entre sí- no debería figurar en una Ley de modificación de la Ley de Arbitraje. La naturaleza jurídica de la técnica creada dista mucho de ser arbitral y, si en algún caso surte efectos arbitrales, lo hace más por error o defectuosa técnica legislativa que por voluntad del legislador, que expresa claramente en la Exposición de Motivos que su pretensión se agota en crear un "cauce procedimental" para resolver cierto tipo de controversias en el marco de las relaciones de coordinación dentro de la Administración del Estado. Esta circunstancia propició la presentación de varias enmiendas durante la tramitación del Proyecto de Ley en el Congreso de los Diputados, en las que se proponía, a mi juicio acertadamente, que la normativa propuesta debería ubicarse en la LOFAGE, por ser el texto dedicado a regular las relaciones organizativas en la Administración del Estado ${ }^{35}$ o, incluso, en la Ley 30/1992 $2^{36}$.

${ }^{35}$ Enmienda número 14 al Proyecto de Ley, presentada por Esquerra Republicana, Izquierda Unida, Iniciativa per Catalunya Verds (de supresión): “ ... No es esta la primera vez que se baraja la posibilidad de incorporar a nuestro ordenamiento jurídico una norma con este contenido, pero sí es la primera vez que pretende ubicarse en un texto tan inidóneo como la Ley de Arbitraje ... ésta es una institución que se basa precisamente en la libertad y voluntariedad del sometimiento, esto es, el principio contrario al que corresponde al precepto cuestionado, que se basa en la obligatoriedad de la sumisión. De ahí que la norma encontraría su mejor ubicación en la Ley 6/1997, de 14 de abril, de Organización y Funcionamiento de la Administración General del Estado, texto dedicado a regular las relaciones organizativas en la Administración estatal". Con esa misma base argumentativa, se cuestiona el apoyo competencial que se hace en la Disposición Final Sexta del Proyecto: en lugar de citarse exclusivamente el artículo 149.1. $6^{\circ}$ y $8^{\circ}$, debería citarse además el artículo $149.1 .5^{\circ}$ y $18^{\circ}$. El texto de la enmienda número 14 se reproduce en la número 48, presentada por el Grupo Parlamentario Catalán (Convergència i Unió), también en lo que respecta a su posible ubicación en la LOFAGE; sin embargo, en una nueva enmienda, la número 49, en este caso de modificación, se propone llevar la regulación contenida en la Adicional a la Ley 30/1992 "Se adiciona una nueva Disposición Adicional Vigésima a la Ley 30/1992, de 26 de noviembre de Régimen Jurídico de las Administraciones Públicas y del Procedimiento Administrativo Común, con la siguiente redacción: (el resto igual)"). Además, propuso también la supresión de la Adicional el Grupo Parlamentario Popular (enmienda número 32), insistiendo en la ida de que "quizás deba ser objeto de una regulación específica, pero no dentro de una Ley de arbitraje "de derecho privado", prevista para solucionar cuestiones sobre materias disponibles", aunque en este caso la fundamentación de la enmienda se centraba en el carácter forzoso del arbitraje, más que en su naturaleza organizativa.

${ }^{36}$ Ibid. La justificación de esta enmienda (número 49) es interesante y refuerza la tesis expuesta: "Despejar cualquier duda acerca de la naturaleza jurídico-administrativa del arbitraje administrativo, así como inserirlo en el sistema de solución de controversias administrativas con plena aplicación de los principios informadores del Derecho Administrativo". 
En segundo lugar, si la técnica expuesta no es arbitral, al menos en sentido propio, no debería utilizarse esta expresión porque no aporta ninguna ventaja y sí, en cambio, un gran inconveniente: contribuir a consolidar o incrementar el confusionismo reinante en nuestro ordenamiento jurídico en esta materia. En esta ocasión, el texto legal acierta al no incluir la expresión "arbitraje" en su articulado porque tiene muy poco que ver con aquél, al menos en la mayoría de los supuestos en que puede resultar aplicado. De ahí que se haga referencia a un "procedimiento" de resolución de controversias. Habría sido un acierto que la misma cautela con la que se ha tratado la técnica en el texto de la Ley se hubiese tenido en el propio título de la norma, en el que sí puede leerse, sin reparos, "regulación del arbitraje institucional en la Administración General del Estado".

En tercer lugar, el calificativo "institucional" que acompaña al término "arbitraje" en el título de la norma es notablemente inconveniente. La expresión "arbitraje institucional" tiene, precisamente en sede arbitral, un contenido muy diferente al que pretende darse en la disposición adicional comentada. En la Ley de Arbitraje - a la que precisamente acompaña la nueva regulación, el arbitraje institucional es aquel en el cual las partes encomiendan la administración del arbitraje y la designación de árbitros a instituciones arbitrales (artículo 14), y se caracteriza precisamente porque quien administra no arbi$\operatorname{tra}^{37}$. Nada tiene que ver, por tanto, con esta idea el "arbitraje institucional" recogido en la Ley 11/2011, por el que se crea una Comisión específica, estable y permanente a la que se le encomienda la resolución de la controversia. Puede decirse a favor de la norma que las cosas son lo que son por su contenido, y no por el nombre que se les da, pero no estaría de más afinar en este tipo de cuestiones si pretendemos salir de una vez por todas del reino de la confusión en el que se ha sumido la técnica arbitral.

\section{LA NATURALEZA JURÍDICA DE LA TÉGNICA PREVISTA EN LA DISPOSICIÓN ADICIONAL ÚNICA DE LA LEY 11/2011}

Como expuse páginas atrás, entre el ente matriz y los llamados entes instrumentales pueden surgir dos tipos de conflictos, según se planteen en el mar-

37 Vid. J.M. ALONSO PUIG, "El arbitraje institucional", Comentarios a la Ley de Arbitraje, A. DE MARTÍN MUÑOZ y S. HIERRO ANIBARRO (Coords.), Marcial Pons, 2006, págs. 679 y ss. 
co o al margen de la relación de instrumentalidad. Ignorando esta realidad, la Ley 11/2011 parece querer dar soporte a todas las situaciones enunciadas, aunque unas y otras sean de muy diferente naturaleza y no admitan la misma técnica de resolución de conflictos.

En el caso de conflictos surgidos a propósito de actuaciones enmarcadas en la llamada relación de instrumentalidad, la naturaleza jurídica del arbitraje institucional no plantea problemas. Obviamente, no será un arbitraje en sentido estricto, porque no es cuasi-jurisdiccional, ni falta que hace. Tratándose de una relación ente matriz - ente instrumental, basta con un procedimiento administrativo específico que permita al primero ejercer sus funciones de dirección sobre el segundo. En este caso, la actuación se encomienda por ley a una Comisión Delegada del Gobierno que representa los intereses generales encomendados a la Administración General del Estado, que son, también, los de sus entes instrumentales.

Es lógica la prohibición de acudir a la vía judicial para resolver este tipo de controversias. Ya existía antes de este ley, como se ha expuesto, al amparo del artículo 20.c) de la Ley Jurisdiccional, al menos respecto a una tipología de entes instrumentales, las entidades de derecho público ${ }^{38}$, que ahora se hace extensible a todos los demás entes instrumentales. Hubiese sido razonable, en cualquier caso, que la Ley 11/2011 contuviese en su disposición final una referencia al artículo 20 LJCA, para incluir a los entes instrumentales a que se refiere el apartado 1 de la adicional única, que no tienen cabida en la redacción actual.

Los actos ejercidos fuera de la relación de instrumentalidad no pueden recibir el mismo tratamiento que los anteriores. La jurisprudencia ha admitido con solidez que en estos casos los entes instrumentales actúan frente a la Administra-

\footnotetext{
38 Cuestión distinta será la posible impugnación de las decisiones de la Comisión Delegada por terceros afectados. En este caso, es evidente que los acuerdos de la Comisión son recurribles, salvo por las partes en conflicto, como reza el precepto legal. En este caso podría tener sentido una enmienda presentada a la Disposición Adicional por el Grupo Catalán (Convergència i Unió), que añadía al texto proyectado un inciso que, a mi juicio, no es válido para todos los supuestos que pueden encajar en el texto: "Los actos o resoluciones tomadas para la solución de estas controversias jurídicas relevantes serán recurribles tanto en vía administrativa como judicial". En su justificación no se dice más que "Se pretende introducir, para mayor claridad, una previsión obvia". Sin embargo, a la vista de los múltiples supuestos de hecho que pueden encajar en la Adicional, la previsión no es obvia ni añade claridad a la regulación. Creo que el inciso solo es válido si se refiere a terceros afectados por la controversia o la decisión de la Comisión.
} 
ción como meras personalidades jurídicas con fines propios, y que la Administración actúa también en el marco de las relaciones de supremacía general, ajena a la relación que les une en la consecución de otros fines compartidos. La consecuencia directa de este reconocimiento es muy clara: en tales casos, no rige la prohibición de interponer recurso contencioso-administrativo contenida en el artículo 20 c) LJCA.

¿Cómo valorar, entonces, el mecanismo legal que, en primer lugar, impone a la Comisión Delegada del Gobierno el dictado de "una resolución estableciendo de forma vinculante para las partes las medidas que cada una de ellas deberá aportar para solucionar el conflicto o controversia planteados" y, en segundo lugar, señala que "la resolución de la Comisión Delegada no será recurrible ante los Tribunales de Justicia por las partes en conflicto"? En estos casos, la Comisión Delegada no actúa como ente coordinador, sino como verdadero árbitro entre las dos partes contendientes, y su decisión, en la medida en que excluye el planteamiento de la controversia en sede jurisdiccional, tiene la fuerza de un laudo arbitral. Es evidente que esta no fue la pretensión del legislador y que, además, difícilmente va a poder legitimarse la actuación de un árbitro que es manifiestamente "parcial" respecto al conflicto, a la vista de su composición netamente gubernamental.

A la vista de lo anterior, creo que habrá que atenerse a las siguientes alternativas:

a) Puede mantenerse el texto vigente e interpretarse en el único sentido admisible. En tal caso, habrán de ser los tribunales de justicia quienes, en la aplicación de la ley y ante una eventual impugnación de actos o disposiciones por parte de entes instrumentales, admitan a trámite el recurso cuando se plantee sobre asuntos ajenos a la relación de instrumentalidad. Lo contrario sería tanto como negar legitimación a quien la tiene, y por tanto incurrir en una vulneración del artículo 24.1 CE.

b) Puede modificarse la ley para ceñir su ámbito de aplicación al que realmente debe ser objeto del procedimiento, para lo cual sería necesario que se declarasen excluidas de su ámbito las controversias ajenas a la relación de instrumentalidad y, como veremos, las surgidas entre entes instrumentales.

c) Si está en el ánimo del legislador excluir de la vía judicial cualesquiera controversias surgidas entre la Administración pública y sus entes instrumentales, o las surgidas entre estos últimos, necesariamente tendría que haberse creado un órgano arbitral muy diferente, por lo pronto, con la exigible impar- 
cialidad respecto de los contendientes. De modo que, conociendo de una controversia nacida de la relación de instrumentalidad o de otra completamente ajena a ella, su decisión pudiera ser imperativa y de obligado cumplimiento para las partes. En unos casos, la fuerza de la decisión sería la propia de una entidad a la que se le habría encomendado una función de coordinación; en otros casos, la fuerza de la decisión provendría de su naturaleza de laudo arbitral.

Incluso podría mantenerse la Comisión Delegada, relegándola en el segundo supuesto (arbitraje stricto sensu) a un papel de "institución arbitral" propiamente dicha (tal es además el nombre que se le da en el título de la Ley). Su función no sería, por tanto, más que la de administrar el arbitraje y designar los árbitros pero nunca resolver la controversia.

Además, y en este último caso, habría sido conveniente establecer una remisión a la Ley 60/2003 respecto a las cuestiones arbitrales que no tienen hoy en día una regulación singular en el ámbito jurídico-público o, por qué no, haber desarrollado algunas cuestiones específicas para este arbitraje, aprovechando la sede en que se formula la técnica, que contiene, precisamente, una modificación de la Ley 60/2003.

Finalmente, debería garantizarse el carácter voluntario del arbitraje, dejando abierta la vía judicial para el caso de que no se llegase a un acuerdo sobre el cauce extrajudicial. En relación con este último inciso, quizá pudiera defenderse una suerte de "arbitraje obligatorio", del estilo del que impuso el artículo 10 del Real Decreto-Ley 17/1977, de 4 de marzo, de reforma de la normativa sobre relaciones de trabajo ${ }^{39}$, en atención a la peculiaridad de los

39 "El Gobierno, a propuesta del Ministerio de Trabajo, teniendo en cuenta la duración o las consecuencias de la huelga, las posiciones de las partes y el perjuicio grave de la economía nacional, podrá acordar la reanudación de la actividad laboral en el plazo que determine, por un período máximo de dos meses o, de modo definitivo, mediante el establecimiento de un arbitraje obligatorio. El incumplimiento de este acuerdo podrá dar lugar a la aplicación de lo dispuesto en los artículos 15 y 16. Cuando la huelga se declare en empresas encargadas de la prestación de cualquier género de servicios públicos o de reconocida e inaplazable necesidad y concurran circunstancias de especial gravedad, la Autoridad gubernativa podrá acordar las medidas necesarias para asegurar el funcionamiento de los servicios. El Gobierno, asimismo, podrá adoptar a tales fines las medidas de intervención adecuadas". El párrafo $1^{\circ}$ de este artículo fue declarado inconstitucional y nulo en lo que respecta a la atribución de la facultad al Gobierno para imponer la reanudación del trabajo, pero no en cuanto le faculta para instituir un arbitraje obligatorio, siempre que en él se respete el requisito de imparcialidad de los árbitros (STC 11/1981, de 8 de abril). 
sujetos contendientes, pero supondría resucitar una figura que, justificada a duras penas en su momento, hoy se compadece mal con la regulación jurídica del arbitraje y el derecho a la tutela judicial efectiva ${ }^{40}$.

En definitiva, de lege lata la disposición adicional única de la Ley 11/2011 recoge una manifestación de la potestad de dirección de la Administración respecto a sus entes instrumentales, pero regula algo más. En algunos de los supuestos sobre los que deberá aplicarse la norma, la resolución de la Comisión Delegada, con la correspondiente prohibición de ventilar la controversia ante los Tribunales de Justicia, es, por su eficacia, un arbitraje obligatorio ${ }^{41}$ de equivalencia jurisdiccional. Serán los tribunales de lo contencioso-administrativo quienes, con total seguridad, tendrán que pronunciarse sobre la idoneidad de la fórmula articulada ${ }^{42}$.

\section{IV. ÁMBITO SUBJETIVO}

Con los matices que se han expuesto y los que más adelante se harán, puede afirmarse que la disposición adicional única de la Ley 11/2011 crea un pro-

40 Vid. la opinión matizada de ROSA MORENO, El arbitraje administratioo, Mc Graw-Hill, Madrid, 1998, pág. 65, que recuerda la posibilidad de positivizar arbitrajes obligatorios como único medio previsto de dirimir determinada clase de conflictos, posibilidad conforme con el texto constitucional según la STC 11/1981, siempre que se den unos presupuestos especiales y esté, en todo caso, garantizada la imparcialidad de los árbitros. No obstante, dice el autor, esta sentencia hace referencia a una muy peculiar relación de sujeción, la funcionarial, por lo que queda el interrogante de su generalización en el Derecho administrativo. Se refiere también a la cuestión F. GARCÍA GÓMEZ DE MERCADO, "Alternativas a la solución judicial de los conflictos con la Administración", Revista española de Derecho Administrativo, número 119, 2003, págs. 414 y ss.

${ }^{41}$ El Grupo Parlamentario Popular presentó una enmienda de supresión de esta Adicional y argumentó, entre otras cosas, el dudoso carácter forzoso de este arbitraje (Boletín del Congreso de los Diputados de 22 de diciembre de 2010, Serie A, Proyectos de Ley, número 85-15, IX legislatura). El carácter forzoso del arbitraje no extraña cuando se impone a las Administraciones públicas o entes instrumentales. La voluntad del órgano o del ente es suplida en este caso por la decisión del legislador. Bien entendido que podrán elevarse a esta Comisión las controversias surgidas entre la Administración matriz y un ente instrumental que no afecten a terceros. No podrán elevarse a la Comisión, por ejemplo, las resoluciones dictadas en alzada por el Ministro cuando desautoricen la decisión recurrida. Si así fuera, en realidad se estaría imponiendo al tercero en cuestión un arbitraje forzoso inadmisible.

42 Vid. un estudio reciente de B. BELANDO GARIN, "El supuesto arbitraje administrativo en la reforma de la Ley 60/2003, de 23 de diciembre”, Diario La Ley, número 7504, 2010. 
cedimiento de resolución de los conflictos que surjan entre la Administración General del Estado y los restantes entes del llamado "sector público estatal" 43.

Centrándonos en la expresión final entrecomillada, forma parte del referido sector público, en primer lugar, un conglomerado de entes públicos, con personalidad jurídica diferenciada, que se reúnen bajo el concepto de "Administración institucional". Son los contemplados en el Título III de la LOFAGE, bajo la denominación de "organismos públicos", y definidos en su artículo 1 como "entidades de Derecho público que desarrollan actividades derivadas de la propia Administración General del Estado, en calidad de organizaciones instrumentales diferenciadas y dependientes de ésta" clasificados de la siguiente forma: a) Organismos autónomos; b) Entidades públicas empresariales; y c) Agencias estatales.

Con diferencias en su regulación y su régimen jurídico, estos organismos públicos tienen por objeto la realización de actividades de ejecución o gestión tanto administrativas de fomento o prestación, como de contenido económico reservadas a la Administración General del Estado (artículo 2.3 de la LOFAGE). Por ello, dependen de ésta y se adscriben directamente o a través de otro

43 Tomando como punto de partida el artículo 2 de la Ley 47/2003, de 26 de noviembre, General Presupuestaria, y aunque la relación se haga a efectos presupuestarios, "forman parte del sector público estatal: a) La Administración General del Estado. b) Los organismos autónomos dependientes de la Administración General del Estado. c) Las entidades públicas empresariales, dependientes de la Administración General del Estado, o de cualesquiera otros organismos públicos vinculados o dependientes de ella. d) Las entidades gestoras, servicios comunes y las mutuas de accidentes de trabajo y enfermedades profesionales de la Seguridad Social en su función pública de colaboración en la gestión de la Seguridad Social, así como sus centros y entidades mancomunados. e) Las sociedades mercantiles estatales, definidas en la Ley de Patrimonio de las Administraciones Públicas. f) Las fundaciones del sector público estatal, definidas en la Ley de Fundaciones. g) Las entidades estatales de derecho público distintas a las mencionadas en los párrafos b) y c) de este apartado. h) Los consorcios dotados de personalidad jurídica propia a los que se refieren los artículos 6, apartado 5, de la Ley 30/1992, de 26 de noviembre, de Régimen Jurídico de las Administraciones Públicas y del Procedimiento Administrativo Común, y 87 de la Ley 7/1985, de 2 de abril, Reguladora de las Bases de Régimen Local, cuando uno o varios de los sujetos enumerados en este artículo hayan aportado mayoritariamente a los mismos dinero, bienes o industria, o se haya comprometido, en el momento de su constitución, a financiar mayoritariamente dicho ente y siempre que sus actos estén sujetos directa o indirectamente al poder de decisión de un órgano del Estado". Téngase en cuenta la Ley 28/2006, de 18 de julio, de Agencias estatales para la mejora de los servicios públicos, que ha creado un nuevo ente instrumental a añadir a los organismos públicos previstos en la LOFAGE. Vid. una lista más exhaustiva en el artículo 3 de la Ley 30/2007, de 30 de octubre, de Contratos del Sector Público. 
organismo autónomo al Ministerio competente por razón de la materia, a través del órgano que en cada caso se determine.

Junto a éstos, las Disposiciones Adicionales Sexta a Novena de la LOFAGE recogen una serie de organismos que se rigen por su legislación específica ${ }^{44}$ y la Adicional Décima fija el régimen jurídico de determinados organismos públicos caracterizados por su especial independencia y autonomía respecto a la Administración General del Estado ${ }^{45}$.

Por otra parte, la Disposición Adicional Duodécima de la LOFAGE recoge las sociedades mercantiles estatales, disponiendo que se regirán íntegramente por el ordenamiento jurídico privado, cualquiera que sea su forma jurídica, salvo en las materias en que les sean de aplicación la normativa presupuestaria, contable, patrimonial, de control financiero y contratación, con la prohibición expresa de disponer de facultades que impliquen el ejercicio de autoridad pública. Se exceptúan de esta previsión las sociedades mercantiles estatales, con forma de sociedad anónima, cuyo capital sea en su totalidad de titularidad, directa o indirecta, de la Administración General del Estado o de sus Organismos públicos, que se rigen por el Título VII de la Ley de Patrimonio de las Administraciones públicas y por el ordenamiento jurídico privado, salvo en las materias en que les sean de aplicación la normativa presupuestaria, contable, de control financiero y contratación ${ }^{46}$.

${ }^{44}$ La Disposición Adicional Sexta se refiere a las entidades gestoras y servicios comunes de la Seguridad Social; la Séptima al Consejo de Estado; la Octava al Banco de España y los Fondos de Garantía de Depósitos en Entidades de Crédito; y la Novena a la Agencia Estatal de Administración Tributaria, el Consejo Económico y Social y el Instituto Cervantes.

${ }^{45}$ Unos son citados expresamente: la Comisión Nacional del Mercado de Valores, el Consejo de Seguridad Nuclear, el Ente Público RTVE, las Universidades no transferidas, la Agencia de Protección de Datos, el Instituto Español de Comercio Exterior (ICEX), el Consorcio de la Zona Especial Canaria, la Comisión Nacional de la Energía, la Comisión del Mercado de las Telecomunicaciones, La Comisión Nacional de la Competencia y la Comisión Nacional del Sector Postal; además, se incluyen con carácter general e innominado aquellos organismos a los que por ley se les reconozca expresamente una independencia funcional o una especial autonomía respecto de la Administración General del Estado (apartado 2).

${ }^{46}$ Se hace, además, una referencia a la Corporación de RTVE, como sociedad estatal dotada de especial autonomía respecto de la Administración General del Estado, que se regirá en primer lugar por su Ley reguladora y sus estatutos sociales; y en segundo lugar por su legislación sectorial y por las normas reguladoras de las sociedades mercantiles estatales en lo que le sean de aplicación y, en defecto de la anterior normativa, por el ordenamiento privado. 
Finalmente, se integran en el sector público estatal las fundaciones reguladas en el Capítulo XI de la Ley 50/2002, de 26 de diciembre, de Fundaciones, constituidas con una aportación mayoritaria, directa o indirecta, de la Administración General del Estado, sus organismos públicos o demás entidades del sector público estatal, o en las que su patrimonio fundacional está formado en más de un $50 \%$ por bienes o derechos aportados o cedidos por dichas entida$\operatorname{des}^{47}$.

De todos ellos, el sistema "arbitral" se aplica a las controversias en que estén implicados la Administración General del Estado, los organismos autónomos, las entidades públicas empresariales, las agencias estatales, la Agencia Estatal de Administración Tributaria, el Consejo Económico y Social, el Instituto Cervantes, las entidades gestoras y los servicios comunes de la seguridad social, las sociedades mercantiles estatales cuyo capital sea en su totalidad de la Administración del Estado o de sus organismos públicos, las fundaciones del sector público estatal y otras entidades de Derecho público que se determinen reglamentariamente.

Llegados a este punto es preciso abordar la tarea antes anunciada, que exige analizar caso por caso la relación entre la Administración General del Estado y cada uno de los entes instrumentales a que afecta la nueva norma, para poder hacer una correcta valoración de las novedades que entraña y de su idoneidad.

Cuando la Ley se refiere a organismos públicos, debemos entender comprendidos en la expresión los organismos autónomos, las entidades públicas empresariales y las agencias estatales (artículo 43 LOFAGE).

Los organismos autónomos se rigen plenamente por el Derecho administrativo y se les encomienda, en régimen de descentralización funcional y en ejecución de programas específicos de la actividad de un Ministerio, la realización de actividades de fomento, prestacionales o de gestión de servicios públicos (artículo 45.1 LOFAGE). Dependen de un Ministerio, al que corresponde la dirección estratégica, la evaluación y el control de los resultados de su actividad, a través del órgano al que esté adscrito el organismo. Además, habrá que atender a la estructura organizativa de cada organismo autónomo para determinar

\footnotetext{
${ }^{47}$ Vid. un magnífico estudio colectivo del sector público estatal en la obra coordinada por A. MORALES PLAZA, M. PARDO GONZÁLEZ y J. RODRIGO LAVILLA, Tratado del sector público estatal, La Ley, 2010.
} 
la posible presencia del Ministro cuando se planteen recursos administrativos contra decisiones de los órganos del organismo autónomo. Si, como regla general, la LOFAGE establece para los organismos públicos adscritos a la Administración General del Estado que agotan la vía administrativa los actos emanados de los máximos órganos de dirección unipersonales y colegiados de acuerdo con lo que establezcan sus estatutos (Disposición Adicional 15 LOFAGE), no faltan excepciones que contemplan el recurso de alzada ante el Ministerio correspondiente ${ }^{48}$.

Lo expuesto para los organismos autónomos resulta aplicable a las entidades públicas empresariales, a las que la LOFAGE define como organismos públicos a los que se encomienda la realización de actividades prestacionales, la gestión de servicios o la producción de bienes de interés público susceptibles de contraprestación (artículo 53.1). Estos organismos, a diferencia de los anteriores, se rigen por el Derecho privado, excepto en la formación de la voluntad de sus órganos, en el ejercicio de las potestades administrativas que tengan atribuidas y en los aspectos específicamente regulados para los mismos en la LOFAGE, en sus Estatutos y en la legislación presupuestaria (apartado 2). Las entidades públicas empresariales dependen de un Ministerio o un organismo autónomo, al que le corresponden las funciones de dirección estratégica, evaluación y control de los resultados de su actividad; les resulta, por lo demás, aplicable lo dicho respecto a los recursos administrativos sobre los organismos autónomos.

Por su parte, las agencias estatales se encuentran a medio camino entre los dos organismos anteriores. Tienen un régimen jurídico ampliamente sujeto al Derecho administrativo, gozan de un mayor nivel de autonomía respecto al órgano que las ha creado y las funciones de dirección estratégica, evaluación y control de resultados y de la actividad de estas agencias se articula a través de un instrumento novedoso: el contrato de gestión, por el cual se delimita la relación existente ente el ente matriz y la Agencia $^{49}$.

48 Vid., por ejemplo, el artículo 82 de la Ley 50/1998, de 30 de diciembre, de medidas fiscales, administrativas y del orden social, que relaciona un total de veintidós organismos públicos en los que los actos y resoluciones de los máximos órganos personales o colegiados no agotan la vía administrativa y son recurribles en alzada ante el Ministro respectivo.

${ }^{49}$ Vid. un estudio de las agencias estatales en la obra colectiva Tratado del Sector Público Estatal, cit., pág. 701 y ss. 
¿Qué aporta la Ley 11/2011 respecto a la regulación en vigor?

En estos momentos, las controversias surgidas entre el Ministerio y los organismos públicos se solventaban con la decisión unilateral del primero y, si surgían fuera de la relación de instrumentalidad, podían llegar a plantearse en sede judicial si quien tenía la responsabilidad de mover la maquinaria procesal era sensible a la doctrina jurisprudencial que elude en estos casos la prohibición contenida en la letra c) del artículo 20 de la Ley Jurisdiccional.

La técnica creada en la adicional única de la Ley 11/2011 tiene, por tanto, en este caso concreto, una consecuencia de escasa trascendencia práctica en todos los conflictos surgidos de la relación de instrumentalidad. A todo lo más, supone una pérdida de poder de dirección del Ministro del ramo a favor de la Comisión Delegada, aunque, dado el carácter gubernamental de la misma y habida cuenta de la personalidad jurídica única de la Administración, no puede darse a esta circunstancia otro valor que el de una medida autoorganizativa.

La conclusión no es la misma si se proyecta sobre controversias ajenas a la relación de instrumentalidad. En estos casos, la exigencia legal de plantear el conflicto ante la Comisión Delegada y la prohibición de hacerlo ante los tribunales de justicia hacen de la técnica un arbitraje forzoso impartido por un árbitro de dudosa imparcialidad.

Junto a los organismos públicos, la Ley se refiere a las sociedades mercantiles y a las fundaciones del sector público.

Respecto a las primeras, es necesario aclarar que la norma se refiere a las sociedades definidas en el artículo 166.2 de la Ley 33/2003, de 3 de noviembre, de Patrimonio de las Administraciones Públicas, es decir, aquéllas cuyo capital es en su totalidad de titularidad, directa o indirecta, de la Administración General del Estado o de sus organismos públicos. En estos casos, la Ley de Patrimonio establece la posibilidad de que, al autorizar su constitución, el Consejo de Ministros atribuya a un ministerio, cuyas competencias guarden una relación específica con el objeto social de la sociedad, la tutela funcional de la misma. De no hacerlo, ejercerá la tutela el Ministerio de Hacienda ${ }^{50}$. Pues

${ }^{50}$ Vid. artículos 178 y ss. La tutela conlleva ejercer el control funcional y de eficacia de las sociedades, dictar instrucciones respecto a las líneas de actuación estratégica, y establecer los sistemas de control que permitan la adecuada supervisión financiera de estas sociedades. Para aquellas sociedades en que sea necesario definir un escenario presupuestario, financiero y de ac- 
bien, es esta relación de "tutela" la que justifica el establecimiento de un cauce de resolución de controversias como el que se regula en la Ley 11/2011, que no debería extenderse, por las razones expuestas, a los conflictos surgidos fuera de dicha relación.

En cuanto a las fundaciones del sector público, a pesar de las múltiples diferencias doctrinales sobre su naturaleza y régimen jurídico ${ }^{51}$, lo cierto es que prestan el servicio público que las justifica a modo de entes descentralizados o funcionales, actuando como verdaderos entes públicos ${ }^{52}$. Las enmiendas número 14 y número 48 presentadas al texto del Proyecto de Ley en el Congreso

tuación a medio plazo, el marco de relaciones con la Administración General del Estado se establecerá preferentemente sobre la base de un convenio o contrato-programa, a iniciativa del ministerio de tutela o de la Dirección General del Patrimonio del Estado, en el caso de sociedades de la Administración General del Estado, o del organismo público que sea titular de su capital

${ }^{51}$ Puede encontrarse una detenida exposición de las diferentes tesis doctrinales en J.C. ALLI TURRILAS, Fundaciones y Derecho Administrativo, Marcial Pons, 2010. Para el autor, las fundaciones son entes públicos, pero es necesario levantar el velo de la institución; entonces encontraremos un patrimonio dotado por el ente público, desprendido relativamente del poder público - pues sigue sometido al control financiero-presupuestario del Estado-, gobernado por personas interpuestas pero dirigidas y dependientes del poder público, y para un fin "de interés general". Llega a firmar que "sin ambages, estamos ante puros organismos autónomos a los que se les ha revestido de fundación, pero arreglando el modelo con recortes y costuras por todos lados". Y concluye: "Por todo ello parece necesario señalar que sería mejor que las funciones del sector público no sean, ni pretendan ser, ni las llamemos más, fundaciones". Cfr. op. cit., pág. 455-456. Vid. sobre las fundaciones del sector público, además de la obra citada, J.L. PIÑAR MAÑAS y A. REAL PÉREZ, Derecho de fundaciones y voluntad del fundador, Marcial Pons, 2000; y, recientemente, T. CARBALLEIRA RIVERA, Fundaciones y Administración Pública, Atelier, 2009.

52 A. MENÉNDEZ REXACH, "Formas jurídicas de gestión de los servicios sanitarios", en L. PAREJO ALFONSO, F. LOBO y M. VAQUER (coords.), La organización de los servicios públicos sanitarios, Marcial Pons, 2001, pág. 91 y ss. En esta dirección, D. VILLAVERDE PAGE analiza alguna jurisprudencia relevante y clarificadora de la naturaleza de entidad pública de las fundaciones del sector público. Por ejemplo, cita la Sentencia de la Sala de lo Contencioso-administrativo del Tribunal Superior de Justicia de Madrid de 27 de enero de 2000 (Sección tercera, número de recurso 83/1999), la cual concluye, respecto de una fundación pública sanitaria que "nos encontramos ante una entidad de Derecho Público de las aludidas en el artículo 1.2 de la Ley 29/1998, de 13 de julio"; asimismo, la Sentencia de 9 de junio de 1988, de la Sala de lo Contencioso-administrativo del Tribunal Supremo, ponente F. González Navarro, en la que se afirma respecto a un Patronato de una fundación pública dependiente de un Ayuntamiento que "la personalidad de la fundación, por más que sea un instrumento útil de cara a facilitar una más ágil gestión no puede hacer perder de vista el carácter de simple órgano que en las relaciones internas tiene aquélla"; y, finalmente, el Auto del Tribunal Constitucional 206/1999, de 28 
ponen de manifiesto una carencia de la Adicional que debería haberse subsanado. Me refiero al inciso en el que, refiriéndose a las fundaciones, se dice:

"Este procedimiento será, asimismo, aplicable a las controversias jurídicas que se susciten entre las sociedades mercantiles estatales y las fundaciones del sector público estatal con su Ministerio de tutela, la Dirección General de Patrimonio o los Organismos o entidades públicas que ostenten la totalidad del capital social o dotación de aquellas, salvo que se establezcan mecanismos internos de resolución de controversias".

En relación con este texto, se señaló por los Grupos Parlamentarios en el Congreso de Esquerra Republicana, Izquierda Unida, Iniciativa per Catalunya Verds (enmienda número 14) y el Catalán (Convergència i Unió) que debería hacerse referencia al Protectorado, en lugar de citar al Ministerio de tutela, la Dirección General de Patrimonio u los Organismos o entidades públicas que ostenten la totalidad de la dotación de las fundaciones. En los términos en que está redactada, "la norma devendría inaplicable a las fundaciones, toda vez que no disponen de Ministerio de tutela, sino que están sujetas al Protectorado, figura jurídica radicalmente distinta; ni es posible que un organismo o entidad ostente su dotación, ya que la dotación es de la propia fundación y no de terceros".

Finalmente, se refiere la Ley a los conflictos que puedan surgir entre entes instrumentales pertenecientes a la Administración General del Estado. Obviamente, pueden surgir este tipo de conflictos, pero pueden ser de muy diversa naturaleza. De ahí que resulte dificil concebir un mecanismo de coordinación de aplicación general a todos ellos, sobre todo porque no existe en estos casos la legitimación invocada del ejercicio del poder de dirección de la Administración matriz sobre sus entes instrumentales o, por utilizar la expresión ya empleada, no existe la citada relación de instrumentalidad.

\section{V. ÁMBITO OBJETIVO}

de julio: "Luego estamos en presencia, por un lado, de un ente privado fundacional que, para lo que aquí interesa, actúa materialmente como un organismo público bajo la dependencia directa de dos Administraciones...". Cfr. "Las fundaciones públicas estatales", en Tratado del Sector Público Estatal, cit., pág. 1578. 
La Ley pretende reconducir a este tipo de arbitraje institucional las controversias "relevantes", que se presumen por razón del número de reclamaciones producidas o que puedan llegar a producirse, por razón de la cuantía o por su relevancia para el interés público:

"Se entenderá por controversias jurídicas relevantes aquellas que, con independencia de su cuantía, generen o puedan generar un número elevado de reclamaciones, que tengan una cuantía económica de al menos 300.000 euros o que, a juicio de una de las partes, sea de esencial relevancia para el interés público".

Lo cierto es que el dato de la "relevancia" se introduce a propósito de las controversias que puedan surgir entre la Administración General del Estado y cualquiera de los organismos públicos regulados en el Título III y la disposición adicional novena de la Ley 6/1997, de organización y funcionamiento de la Administración General del Estado, o las entidades gestoras y servicios comunes de la Seguridad Social, u otras entidades de Derecho público reguladas por su legislación específica que se determinen reglamentariamente, o entre dos o más de estos entes. Cuando el precepto regula las controversias con las sociedades mercantiles estatales y las fundaciones omite el calificativo de "relevantes"; no creo, pese a ello, que tenga ningún sentido la distinción y supongo que se tratará de un lapsus o una defectuosa redacción que deberá subsanarse en cuanto haya la ocasión de hacerlo.

Sin perjuicio de lo anterior, se excluyen de este tipo de arbitraje ciertas controversias por razón de su materia:

"Este procedimiento de resolución de controversias no se aplicará:

a) A cuestiones de naturaleza penal, pero sí a las relativas al ejercicio de acciones civiles derivadas de delitos y faltas.

b) A cuestiones de responsabilidad contable que sean competencia del Tribunal de Cuentas, sujetas a la legislación específica reguladora de éste.

c) A conflictos de atribuciones entre distintos órganos de una misma Administración Pública, que se regularán por sus disposiciones específicas.

d) A las cuestiones de las actuaciones de control efectuadas por la intervención general de la Administración del Estado, reguladas con carácter específico en la Ley 47/2003, de 26 de noviembre, General Presupuestaria, en la Ley 38/2003, de 17 de noviembre, General de Subvenciones, y demás normas de desarrollo de las mismas". 


\section{LA COMISIÓN DELEGADA DEL GOBIERNO}

Una de las novedades más llamativas de la nueva regulación legal es la creación de una Comisión Delegada del Gobierno para la Resolución de las Controversias Administrativas. Forman parte de esta Comisión varios Ministros, entre ellos el de la Presidencia, que será su presidente, el Ministro de Economía y Hacienda y el Ministro de Justicia, como vocales natos, y el Ministro o Ministros de los departamentos afectados por la controversia. La secretaría será ejercida por quien designe el Ministro de Justicia dentro de su ámbito. Es decir, es una Comisión netamente gubernamental.

La composición de la Comisión es coherente con la idea que se transmite en la Exposición de Motivos del Proyecto: pretende regular un cauce procedimental de carácter ordinario e institucional para que el Gobierno resuelva los conflictos internos entre la Administración General del Estado y sus Entes instrumentales. No se persiguen, como es obvio, objetivos de neutralidad, porque en ese caso la Comisión, más que ser Delegada del Gobierno, tendría que ser independiente de éste; ni el Gobierno tiene la más mínima intención de renunciar a su poder de dirección sobre estos entes instrumentales.

No se alcanzan a vislumbrar otras ventajas derivadas de la existencia de una Comisión Delegada que la de lograr la unificación de líneas de dirección dentro del mismo Gobierno, hasta ahora no alcanzada necesariamente al recaer las acciones de dirección sobre los distintos Ministerios. No es una razón despreciable, pero a mi juicio no justifica que se utilice el calificativo de "arbitraje institucional" en el título de la Ley y de su adicional única ni, mucho menos, que se haya escogido la ocasión de reformar la Ley 60/2003 para crear esta Comisión.

Por lo demás, poco se dice en el texto legal sobre el funcionamiento de la Comisión Delegada:

- Planteada una controversia, las partes enfrentadas la pondrán, de forma inmediata, en conocimiento de la Comisión Delegada del Gobierno para la Resolución de Controversias Administrativas.

- La Comisión Delegada recabará los informes técnicos y jurídicos que estime necesarios para el mejor conocimiento de la cuestión debatida.

- Por la secretaría de dicha Comisión se elaborarán las propuestas de decisión oportunas. 
- La Comisión Delegada dictará resolución estableciendo de forma vinculante para las partes las medidas que cada una de ellas deberá adoptar para solucionar el conflicto o controversia planteados.

- La resolución de la Comisión Delegada no será recurrible ante los Tribunales de Justicia por las partes en conflicto.

Dada la brevedad con que se tratan las cuestiones procedimentales, habría sido conveniente hacer una remisión a futuros reglamentos o a la Ley 30/1992 para los aspectos no regulados. Habrá que esperar, en definitiva, al desarrollo reglamentario del texto legal.

\section{RECAPITULACIÓN}

La aprobación de la Ley 11/2011 ha constituido en sí misma una buena noticia, porque supuso revivir una línea de discusión que parecía agotada después del fracasado Anteproyecto de Ley de Arbitraje Público del año 2001. El mero hecho de que se haya tomado la decisión de alejar de los Tribunales de Justicia una fuente de conflictos, por más que en la práctica ya se estuviese haciendo por vía reaccional invocando el artículo 20.c) de la Ley Jurisdiccional, presupone en quien ha tomado la iniciativa mucho pragmatismo y sentido común.

Ahora bien, si todo lo que puede decirse de la novedad legislativa se resume en mis palabras anteriores, entonces habrá que aceptar que la iniciativa es limitada, insuficiente y muy decepcionante.

En primer lugar, si el resultado que se espera obtener de la adicional única de la Ley es meramente organizativo y no excede del ámbito de la coordinación de la Administración General del Estado con sus entes instrumentales, demasiada alforja para tan corto viaje. Y qué decir del vehículo escogido: la modificación de una ley de arbitraje privado que pivota sobre un principio elemental, el de la autonomía de la voluntad, tan antitético al principio de dirección que le acompaña en forma de disposición adicional. Hubiese bastado una medida tan sencilla como aprovechar el Proyecto de Ley de Economía Sostenible, de tramitación casi coincidente en el tiempo con la Ley 11/2011, para añadir una adicional en la LOFAGE o en la Ley 30/1992, porque cualquiera de estos dos cuerpos legales habría tolerado con mayor naturalidad el injerto ${ }^{53}$.

${ }^{53}$ En esta línea, el Grupo Parlamentario Popular en el Congreso presentó una enmienda de 
En segundo lugar, la sensación que puede provocar el texto legal de que nuevamente se abre el debate sobre el arbitraje de Derecho público se desvanece cuando se profundiza en las medidas aprobadas. Nada más lejos de la realidad. La Ley 11/2011 no recoge un arbitraje en sentido estricto, sino un procedimiento administrativo revestido de una terminología típicamente arbitral, como si quisiera disfrazarse aquél para encajar, sin forzar demasiado, en una Ley de reforma de la Ley de Arbitraje. Utilizando una expresión coloquial, el hábito no hace al monje.

En tercer lugar, la mayor decepción proviene de la conciencia de haber perdido una ocasión inmejorable. Si era el momento de reformar la Ley de 2003, qué buena noticia habría sido que se añadía un nuevo título referido a las especialidades del arbitraje en las contiendas jurídico-públicas. Puede discutirse si es conveniente o no que el arbitraje privado y el público compartan norma reguladora. Dependerá de la dimensión que se dé a las particularidades de éste frente a aquél, que podrían ser tantas y de tal relevancia que nada más que la coincidencia del nomen justificaría una regulación conjunta. A mi juicio, no son tan extrañas las técnicas como para necesitar de dos textos legales diferentes. Y, desde un punto de vista pragmático siempre será preferible una mejorable Ley de arbitraje privado y público que una Ley de arbitraje privado y una ausencia de regulación legal del público, que es con lo que ahora contamos.

En definitiva, una ocasión perdida o medio aprovechada. Habrá que confiar en que la situación angustiosa de la Justicia lleve, por fin, al Gobierno, a presentar un Proyecto de Ley específico sobre el Arbitraje en las relaciones jurídico-públicas en el que tengan cabida, también, algunas de las controversias a las que aludí en las páginas precedentes ${ }^{54}$.

supresión contra esta Adicional (Boletín del Congreso de los Diputados de 22 de diciembre de 2010, Serie A, Proyectos de Ley, número 85-15, IX legislatura): "Quizás debe ser objeto de una regulación específica, pero no dentro de una ley de arbitraje de "Derecho privado", prevista para solucionar cuestiones sobre materias no disponibles".

54 Será una ocasión magnífica para rescatar de las arcas del olvido los magníficos trabajos realizados por la doctrina española sobre la cuestión y, en concreto, por la escuela sevillana de Derecho Administrativo, protagonista de excepción del único intento palpable de elaboración de un anteproyecto de ley de arbitraje administrativo (2001). En el apartado bibliográfico se da cuenta de algunas obras referentes en esta materia. 


\section{BIBLIOGRAFÍA SELECGIONADA SOBRE ARBITRAJE ADMINISTRA- TIVO:}

BELANDO GARIN, B., "El supuesto arbitraje administrativo en la reforma de la Ley 60/2003, de 23 de diciembre", Diario La Ley, número 7504, 2010.

BUSTILLO BOLADO, R., Convenios y contratos administrativos: transacción, arbitraje y terminación convencional del procedimiento, Ed. Aranzadi, $1^{\text {a }}$ ed., 2001, $3^{\text {a }}$ ed., 2010.

FERNÁNDEZ MONTALVO, R., TESO GAMELLA, P. y AROZAMENA LASO, A., El arbitraje: ensayo de alternativa limitada al recurso contencioso-administrativo, Consejo General del Poder Judicial, 2004.

FERRET JACAS, J., "Límites del arbitraje administrativo", Revista Andaluza de Administración Pública, número 35, 1999.

GARCÍA GÓMEZ DE MERCADO, F., "Alternativas a la solución judicial de los conflictos con la Administración", Revista española de Derecho Administrativo, número 119, 2003.

GARCÍA PÉREZ, M., Arbitraje y Derecho Administrativo, Thomson-Cívitas, 2011.

GONZÁLEZ CUETO, T., "El arbitraje como medio en la solución de controversias cuando son parte las Administraciones Públicas, convenios de colaboración y otras fórmulas", La asistencia jurídica al Estado e instituciones públicas, Aranzadi, 1995.

GONZÁLEZ-VARAS IBÁÑEZ, S., "Las negociaciones y el Derecho administrativo.: transacciones, convenios, arbitraje", El Derecho público a comienzos del siglo XXI. Estudios en Homenaje al Profesor Allan R. Brewer Carías, Tomo II, Ed. Thomson Cívitas, 2003.

HUERGO LORA, La resolución extrajudicial de conflictos en el Derecho administrativo, Publicaciones del Real Colegio de España, Bolonia, 2000.

LÓPEZ MENUDO, F., "Arbitraje y Derecho Público", Justicia Administrativa, número 2, 1999.

MARESCA CABOT, J.C., "El arbitraje en Derecho administrativo", Bulletí número 5 del Tribunal Arbitral de Barcelona, 1994; "El arbitraje en la LRJAAPP y de PAC", Bulleti número 6 del Tribunal Arbitral de Barcelona, 1995.

MONTORO CHINER, M.J., "Técnicas pre y extra-procesales de resolución de los conflictos urbanísticos", Bulletí número 9 del Tribunal Arbitral de Barcelona, 1997.

PAREJO ALFONSO, "Algunas reflexiones sobre el "arbitraje administrativo" a propósito de la adecuación al nuevo procedimiento administrativo común del ordenamiento de la Comunidad Autónoma de Madrid", Asamblea. Revista parlamentaria de la Asamblea de Madrid, número 1, 1999. 
PÉREZ MORENO, A., "El arbitraje administrativo", Revista Andaluza de Administración Pública, número 43, 2001.

RIVERO GONZÁLEZ, M., "La abogacía del estado y los conflictos interadministrativos (propuesta de norma legal sobre arbitraje de derecho público)", La asistencia jurídica del Estado en el siglo XXI. Primer Congreso de la Abogacía del Estado, Aranzadi, 2000.

RIVERO ORTEGA, R., "Repensando el Estado de Derecho: el arbitraje administrativo como alternativa al colapso jurisdiccional en el control de la Administración", El Derecho administrativo en el umbral del siglo XXI: Homenaje al Profesor Dr. D. Ramón Martín Mateo (Coord.: F. SOSA WAGNER), Tomo II, Ed. Tirant Lo Blanch, Valencia, 2000.

RODRIGO LAVILLA, J., "Arbitraje y Administración del Estado", Diario La Ley, número 7153, 2009.

ROSA MORENO, J., El arbitraje administrativo, McGraw-Hill, Madrid, 1998.

SÁNCHEZ MORON, M., El control de las Administraciones Públicas y sus problemas, Madrid, 1991.

TORNOS MAS, J., "La situación actual del proceso contencioso-administrativo", Revista de Administración Pública, número 122, 1990; "El arbitraje en Derecho administrativo: posibilidad de esta figura", Bulleti $n^{\circ} 6$ del Tribunal Arbitral de Barcelona, 1995; "Medios complementarios a la resolución jurisdiccional de los conflictos administrativos", Revista de Administración Pública, número 136, 1995.

TRAYTER JIMÉNEZ, J.M., "El arbitraje de Derecho administrativo", Revista de Administración Pública, número 143, 1997. 